\title{
TOX expression in cutaneous T-cell lymphomas: an adjunctive diagnostic marker that is not tumour specific and not restricted to the $\mathrm{CD}_{4}{ }^{+} \mathrm{CD}^{-}$phenotype
}

\author{
A.M.R. Schrader, ${ }^{1}$ P.M. Jansen ${ }^{1}$ and R. Willemze ${ }^{2}$ \\ ${ }^{1}$ Department of Pathology and ${ }^{2}$ Department of Dermatology, Leiden University Medical Centre, Leiden, the Netherlands \\ Linked Comment: Kempf. Br J Dermatol 2016; 175:248-249
}

\section{Summary}

\section{Correspondence \\ Anne M. R. Schrader. \\ E-mail: a.m.r.schrader@lumc.nl \\ Accepted for publication \\ 23 February 2016 \\ Funding sources \\ None. \\ Conflicts of interest \\ None declared. \\ DOI $10.1111 /$ bjd. 14508}

Background TOX (thymocyte selection-associated high-mobility group box) was shown to be aberrantly expressed in mycosis fungoides (MF) and Sézary syndrome (SS) and is suggested to have additional diagnostic value. However, data on expression in other types of cutaneous T-cell lymphoma (CTCL) are scarce and it is unknown whether TOX is expressed only by MF with a $\mathrm{CD}^{+}{ }^{+} \mathrm{CD} 8^{-}$phenotype.

Objectives To investigate TOX expression in various types of CTCL with different T-cell phenotypes.

Methods Immunohistochemical expression of TOX was evaluated on 153 skin biopsies of 132 patients with CTCL and 60 patients with benign inflammatory dermatoses (BIDs).

Results TOX was expressed by $>50 \%$ of the neoplastic T cells in 49 of 59 patients (83\%) with MF and in 19 of 22 patients (86\%) with SS. The TOX ${ }^{+}$cases of MF included 34 of 35 cases (97\%) with a $\mathrm{CD}^{+}{ }^{+} \mathrm{CD} 8^{-}$phenotype, but also five of eight cases $(63 \%)$ with a $\mathrm{CD}^{-} \mathrm{CD}^{+}$phenotype and 10 of 16 cases (63\%) with a $\mathrm{CD}^{-}{ }^{-} \mathrm{CD} 8{ }^{-}$phenotype. TOX expression in other types of CTCL was common but showed variable intensity. Although only one of 60 patients (2\%) with a BID expressed TOX in $>50 \%$ of the skin-infiltrating T cells, some caution is warranted, as the majority of BIDs had TOX ${ }^{+}$T cells varying between $11 \%$ and $50 \%$.

Conclusions TOX expression is not tumour specific, is not restricted to CTCL with a $\mathrm{CD}^{+} \mathrm{CD}^{-}$phenotype, and, on its own, is insufficient for diagnosis of CTCL. However, it may have an adjunctive diagnostic role in conjunction with other clinical and histological data.

\section{What's already known about this topic?}

- TOX is associated with development of $\mathrm{CD}^{+} \mathrm{CD}^{-} \mathrm{T}$ cells in the thymus, but is suppressed in mature $\mathrm{CD} 4^{+} \mathrm{T}$ cells.

- TOX is aberrantly expressed in mycosis fungoides and Sézary syndrome.

\section{What does this study add?}

- TOX is expressed by various types of cutaneous T-cell lymphoma (CTCL), but also - although less strongly and less frequently - by reactive $\mathrm{T}$ cells in benign inflammatory dermatoses.

- Expression of TOX is not restricted to $\mathrm{CD} 4^{+} \mathrm{CD}^{-}$(neoplastic) $\mathrm{T}$ cells.

- TOX expression may contribute to the diagnosis of CTCL.
The major subtypes of cutaneous T-cell lymphoma (CTCL) are mycosis fungoides (MF) and Sézary syndrome (SS). ${ }^{1}$ Both clinically and histologically, it can be difficult to distinguish the early stages of MF and SS from benign inflammatory dermatoses (BIDs) such as atopic dermatitis and psoriasis, and the diagnostic process often leads to a delay that can extend up to many years. 
Recently, gene expression profiling and additional immunohistochemistry have suggested that TOX (thymocyte selectionassociated high-mobility group box) may be considered as a potential marker for the histological diagnosis of early-stage $\mathrm{MF}^{2}$

In 2002, TOX was firstly described by Wilkinson et al. ${ }^{3}$ as part of the superfamily of high-mobility group box proteins that act as regulators of gene expression, mainly by modifying the chromatin structure. ${ }^{3,4}$ In T-cell development, TOX is highly expressed in the thymus during $\beta$-selection and positive selection of $\mathrm{CD}^{+}{ }^{+} \mathrm{CD} 8^{+}$precursors to $\mathrm{CD} 4^{+} \mathrm{T}$ cells, but it is downregulated in mature $\mathrm{CD} 4^{+} \mathrm{T}$ cells once they leave the thymus. ${ }^{3,5}$

Following the first publication by Zhang et al., ${ }^{2}$ several studies have confirmed that TOX is aberrantly expressed in $\mathrm{CD} 4^{+} \mathrm{CD} 8^{-}$neoplastic $\mathrm{T}$ cells in $\mathrm{MF}$ and SS, but not or only rarely by skin-infiltrating $\mathrm{T}$ cells in BIDs. ${ }^{2,6-12}$ Data on expression in other types of CTCL are scarce, and it is unknown whether TOX can also be expressed by cases of $\mathrm{MF}$ with $\mathrm{T}$-cell phenotypes other than $\mathrm{CD} 4^{+} \mathrm{CD} 8^{-}$. Therefore, in the present study, we performed immunohistochemistry for TOX on a large group of CTCLs to evaluate expression among various subtypes of CTCL with different T-cell phenotypes.

\section{Materials and methods}

Formalin-fixed and paraffin-embedded (FFPE) skin biopsies from 132 patients with different types of CTCL were included in this study (Table 1). In all cases, diagnosis was made by an expert panel of dermatologists and pathologists at one of the regular meetings of the Dutch Cutaneous Lymphoma Group, according to the criteria of the World Health Organization-European Organisation for Research and Treatment of Cancer 2005 classification of cutaneous lymphomas. ${ }^{1}$ In 21 patients, a second FFPE skin biopsy from a later date was available. As controls, FFPE skin biopsies of 60 patients with different types of BID were selected (Table 1).

All skin biopsies were collected from the archives of the Department of Pathology, Leiden University Medical Center (LUMC), Leiden, the Netherlands. The study was performed in accordance with the Declaration of Helsinki and the Dutch Code for Proper Secondary Use of Human Tissue, approved by the medical ethics committee of the LUMC. Fifteen of the patients with SS and 17 patients with an erythrodermic BID were also included in a previous study by our group. ${ }^{11}$

Sections from all FFPE skin biopsies were routinely haematoxylin-eosin stained. Additionally, depending on the differential diagnosis, selections of the following immunostains were used: CD2, CD3, CD4, CD5, CD7, CD8, CD20, CD79a, PAX5, programmed death (PD)-1, CD30, ALK, CD1a, CD56, CD68, Ki-67, T-cell receptor (TCR)- $\beta$ F 1 and TCR- $\gamma$. For the purpose of this study, sections of the biopsies were automatically stained using Dako Autostainer Link 48 (Dako, Glostrup, Denmark)
Table 1 TOX expression in different types of cutaneous T-cell lymphoma and benign inflammatory dermatoses

\begin{tabular}{|c|c|c|c|}
\hline & \multicolumn{3}{|c|}{ Amount of TOX expression } \\
\hline & $<10 \%$ & $11-50 \%$ & $>50 \%$ \\
\hline Mycosis fungoides $(n=59)$ & $3(5)$ & $7(12)$ & $49(83)$ \\
\hline Early stage $(\mathrm{n}=41)$ & $2(5)$ & $7(17)$ & $32(78)$ \\
\hline Advanced stage $(\mathrm{n}=18)$ & $1(6)$ & 0 & $17(94)$ \\
\hline Sézary syndrome $(n=22)$ & 0 & $3(14)$ & $19(86)$ \\
\hline 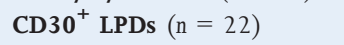 & $5(23)$ & $2(9)$ & $15(68)$ \\
\hline C-ALCL $(\mathrm{n}=11)$ & $4(36)$ & $1(9)$ & $6(55)$ \\
\hline $\begin{array}{l}\text { Lymphomatoid papulosis } \\
\qquad(\mathrm{n}=11)\end{array}$ & $1(9)$ & $1(9)$ & $9(82)$ \\
\hline SPTCL $(n=2)$ & $1(50)$ & $1(50)$ & 0 \\
\hline $\begin{array}{l}\text { PTCL, unspecified and rare } \\
\text { subtypes }(\mathrm{n}=27)\end{array}$ & $2(8)$ & $1(4)$ & $23(88)$ \\
\hline PTCL-NOS $(\mathrm{n}=7)$ & 0 & $1(14)$ & $6(86)$ \\
\hline CGDTCL $(n=2)$ & 0 & 0 & $2(100)$ \\
\hline $\operatorname{AETCL}(\mathrm{n}=3)$ & $2(67)$ & 0 & $1(33)$ \\
\hline PCSM-TCL $(\mathrm{n}=15)$ & 0 & 0 & $15(100)^{\mathrm{a}}$ \\
\hline BPDCN $(n=3)$ & $3(100)$ & 0 & 0 \\
\hline $\begin{array}{l}\text { Benign inflammatory } \\
\text { dermatoses }(n=60)\end{array}$ & $24(40)$ & $35(58)$ & $1(2)$ \\
\hline Atopic dermatitis $(\mathrm{n}=12)$ & $4(33)$ & $8(67)$ & 0 \\
\hline Psoriasis $(n=10)$ & $5(50)$ & $5(50)$ & 0 \\
\hline $\begin{array}{l}\text { Drug-induced dermatitis } \\
\qquad(\mathrm{n}=9)\end{array}$ & $5(56)$ & $3(33)$ & $1(11)$ \\
\hline $\begin{array}{l}\text { Idiopathic erythroderma } \\
\qquad(\mathrm{n}=9)\end{array}$ & $3(33)$ & $6(67)$ & 0 \\
\hline Lichen planus $(\mathrm{n}=7)$ & 0 & $7(100)$ & 0 \\
\hline Lupus erythematosus $(\mathrm{n}=6)$ & $4(67)$ & $2(33)$ & 0 \\
\hline Other $^{b}(n=7)$ & $3(43)$ & $4(57)$ & 0 \\
\hline
\end{tabular}

Values are $\mathrm{n}(\%)$. TOX, thymocyte selection-associated highmobility group box; LPD, lymphoproliferative disorder; C-ALCL, primary cutaneous anaplastic large-cell lymphoma; SPTCL, subcutaneous panniculitis-like T-cell lymphoma; PTCL, peripheral Tcell lymphoma; PTCL-NOS, PTCL, not otherwise specified; CGDTCL, primary cutaneous $\gamma \delta$-positive T-cell lymphoma; AETCL, aggressive epidermotropic $\mathrm{CD} 8^{+} \mathrm{T}$-cell lymphoma; PCSM-TCL, primary cutaneous $\mathrm{CD} 4^{+}$small/medium-sized pleomorphic T-cell lymphoma; BPDCN, blastic plasmacytoid dendritic-cell neoplasm. ${ }^{\mathrm{a}} \mathrm{In} \mathrm{CD} 4^{+}$medium/large-sized pleomorphic T cells. ${ }^{b}$ Patients with fungal infections $(n=2)$, viral exanthema $(n=1)$, graft-versus-host disease $(n=1)$, panniculitis $(n=1)$, inflammatory reaction to a basal cell carcinoma $(\mathrm{n}=1)$ and paraneoplastic erythroderma $(n=1)$.

with rabbit antihuman TOX antibodies from Sigma-Aldrich (HPA018322; St. Louis, MO, U.S.A.) at a dilution of 1 : 200.

The 32 cases of SS or erythrodermic BID that had been included in a previous study of our group were restained automatically. Sections of reactive lymph nodes and tonsils were used as external controls. The sections were scored synchronously by all three authors until consensus was reached. The percentage of $\mathrm{TOX}^{+}$neoplastic $\mathrm{T}$ cells was estimated as $<10 \%, 11-50 \%$ or $>50 \%$. The intensity of the staining was scored as dim or strong. 


\section{Results}

\section{Mycosis fungoides}

Seventy-three biopsies of 59 patients with MF were studied. In early-stage MF (stages IA-IB), staining of $>50 \%$ of the neoplastic T cells was observed in 32 of 41 patients (78\%), including 23 of 24 patients $(96 \%)$ with a $\mathrm{CD} 4^{+} \mathrm{CD} 8^{-}$phenotype, five of eight patients $(63 \%)$ with a $\mathrm{CD} 4^{-} \mathrm{CD} 8^{+}$phenotype (Fig. 1) and four of nine patients (44\%) with a CD4 ${ }^{-} \mathrm{CD} 8^{-}$ phenotype. Of these cases, 29 of 32 (88\%) expressed TOX in $>75 \%$ of the neoplastic $\mathrm{T}$ cells. In advanced-stage MF (stages IIB-IV), 16 patients had tumour-stage disease, including nine with a $\mathrm{CD} 4^{+} \mathrm{CD} 8^{-}$phenotype and seven with a $\mathrm{CD} 4^{-} \mathrm{CD} 8^{-}$ phenotype. Two patients had erythrodermic MF, both with a $\mathrm{CD} 4{ }^{+} \mathrm{CD} 8^{-}$phenotype. TOX was expressed by $>75 \%$ of the neoplastic $\mathrm{T}$ cells in all patients with advanced-stage MF, except for one patient with a $\mathrm{CD}^{-} \mathrm{CD}^{-}$phenotype. In 13 of 14 patients (93\%), second biopsy specimens were consistent in TOX expression. Overall, the intensity of staining of $\mathrm{TOX}^{+}$neoplastic T cells was strong and comparable between all cases.

\section{Sézary syndrome}

In 19 of 22 patients with SS (86\%), TOX was expressed in $>50 \%$ of the Sézary cells, and in 17 of these 19 patients in $>75 \%$. Automatic restaining of the cases that were manually stained in a previous study of our group ${ }^{11}$ corresponded in 14 of 15 patients (93\%). TOX expression in SS was remarkably strong, especially in the Pautrier microabscesses and scattered epidermotropic T cells.

\section{CD30-positive T-cell lymphoproliferative disorders}

In cutaneous anaplastic large-cell lymphoma, TOX expression in $>50 \%$ of the $\mathrm{CD}^{+} 0^{+} \mathrm{T}$ cells was observed in six of 11 patients (55\%), including five of seven (71\%) with a $\mathrm{CD}^{+} \mathrm{CD}^{-}$phenotype, one of three (33\%) with a $\mathrm{CD} 4^{-} \mathrm{CD} 8^{-}$phenotype and none of one $(0 \%)$ with a $\mathrm{CD} 4^{+} \mathrm{CD} 8{ }^{+}$phenotype. In lymphomatoid papulosis, staining in $>50 \%$ of the $\mathrm{CD} 30^{+} \mathrm{T}$ cells was noted in nine of 11 patients (82\%), of whom three of five $(60 \%)$ had a $\mathrm{CD} 4^{+} \mathrm{CD} 8^{-}$phenotype, one of one $(100 \%)$ had a $\mathrm{CD} 4^{-} \mathrm{CD} 8^{+}$phenotype, four of four $(100 \%)$ had a $\mathrm{CD} 4^{-} \mathrm{CD} 8^{-}$phenotype and one of one (100\%) had a CD $4^{+} \mathrm{CD}^{+}$phenotype. TOX expression was consistent in four of five patients $(80 \%)$ with two biopsy specimens. The intensity of TOX expression in $\mathrm{CD} 30^{+}$LPDs was variable between dim and strong within and between the different cases.

\section{Subcutaneous panniculitis-like T-cell lymphoma}

Both patients with subcutaneous panniculitis-like T-cell lymphoma had TOX expression in $<25 \%$ of the (mostly rimming) neoplastic $\mathrm{CD} 4^{-} \mathrm{CD} 8^{+} \mathrm{T}$ cells.

\section{Peripheral T-cell lymphoma, unspecified and rare subtypes}

In cutaneous peripheral T-cell lymphoma, not otherwise specified (PTCL-NOS), TOX was expressed by $>50 \%$ of the neoplastic $\mathrm{T}$ cells in six of seven patients $(86 \%)$, including five of six with a $\mathrm{CD} 4^{+} \mathrm{CD} 8^{-}$phenotype and one of one with a $\mathrm{CD} 4^{-} \mathrm{CD} 8^{+}$phenotype. The intensity of TOX expression in PTCL-NOS was variable.

Both patients with cutaneous $\gamma \delta$-positive T-cell lymphoma and one of three patients (33\%) with aggressive epidermotropic $\mathrm{CD}^{+}$T-cell lymphoma (AETCL) showed strong TOX expression in $>75 \%$ of the neoplastic $\mathrm{CD}^{+} \mathrm{CD} 8^{-}$ $\mathrm{T}$ cells and $\mathrm{CD}^{-} \mathrm{CD}^{+} \mathrm{T}$ cells, respectively. The two other cases of AETCL were completely negative with a positive internal control. In all 16 biopsies of 15 patients

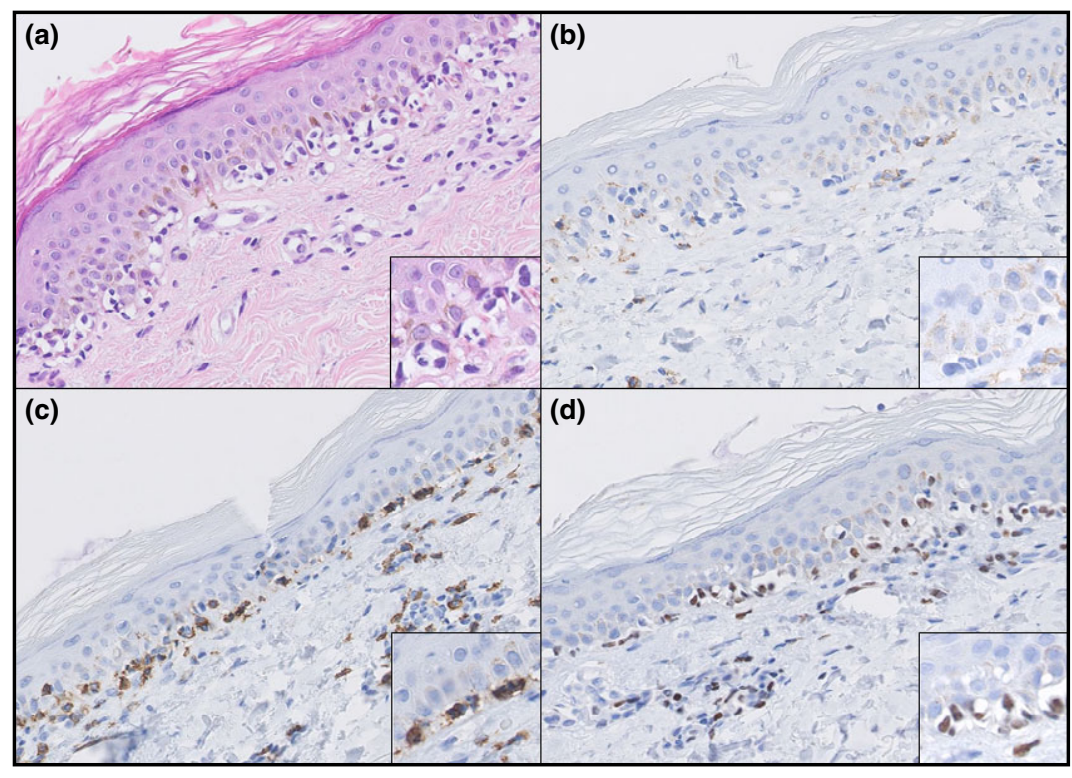

British Journal of Dermatology (2016) 175, pp382-386
Fig 1. Histopathology of a patient with mycosis fungoides with a $\mathrm{CD} 4^{-} \mathrm{CD} 8^{+}$ phenotype. (a) Haematoxylin-eosin staining shows epidermotropism of $\mathrm{CD}^{-}$(b) and $\mathrm{CD}^{+}$(c) neoplastic $\mathrm{T}$ cells along the basal layer. (d) TOX is expressed in $>75 \%$ of the neoplastic T cells. Magnification $\times 200$; insets $\times 400$. 


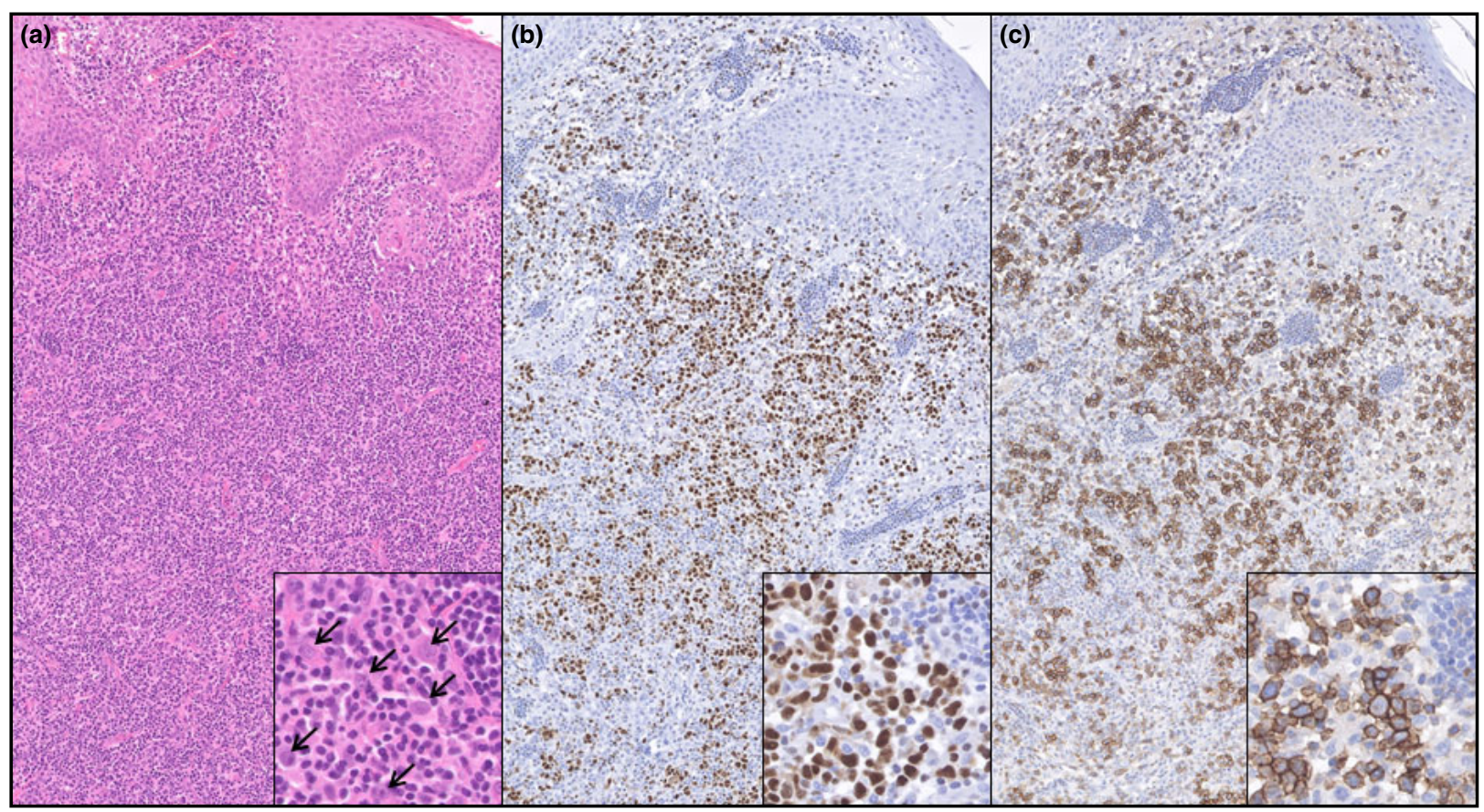

Fig 2. Histopathology of a patient with primary cutaneous $\mathrm{CD}^{+}$small/medium-sized pleomorphic T-cell lymphoma. (a) Haematoxylin-eosin staining shows infiltration of the dermis by a mixed infiltrate in which scattered medium/large-sized pleomorphic cells (inset, arrows) stain strongly positive for TOX (b) and programmed death-1 (c). Magnification $\times 100$; insets $\times 400$.

with primary cutaneous $\mathrm{CD}^{+}$small/medium-sized T-cell lymphoma (PCSM-TCL), scattered medium/large-sized pleomorphic $\mathrm{T}$ cells stained strongly positive with TOX (Fig. 2). Serial sections demonstrated that these were the same $\mathrm{T}$ cells expressing $\mathrm{PD}-1$, as described in a previous study. ${ }^{13}$

\section{Blastic plasmacytoid dendritic-cell neoplasm}

In all three cases of blastic plasmacytoid dendritic cell neoplasm, TOX was negative or weakly expressed by $<10 \%$ of the neoplastic cells.

\section{Benign inflammatory dermatoses}

In BIDs, TOX was expressed by $<50 \%$ of the inflammatory T cells in 59 of 60 cases (98\%), of which 24 of 59 (41\%) were scored as $<10 \%$. Only one patient $(2 \%)$, with a drug-induced dermatitis, showed staining in $>50 \%$ of the inflammatory lymphocytes. In general, the intensity of TOX expression was dim. However, strong staining was observed in a few scattered blasts and epidermotropic lymphocytes, in particular in cases of atopic dermatitis. Additional immunophenotyping with Tcell antigens showed that the $\mathrm{TOX}^{+}$epidermotropic $\mathrm{T}$ cells had mainly a $\mathrm{CD} 4^{-} \mathrm{CD} 8^{+}$phenotype (Fig. 3).
Fig 3. Histopathology of a patient with atopic dermatitis. (a) Haematoxylin-eosin staining shows superficial perivascular infiltrates and exocytosis of lymphocytes. These intraepidermal lymphocytes are predominantly $\mathrm{CD}^{-}$(b) and $\mathrm{CD}^{+}$(c), and the majority stain positive for TOX (d). Magnification $\times 100$; insets $\times 400$.

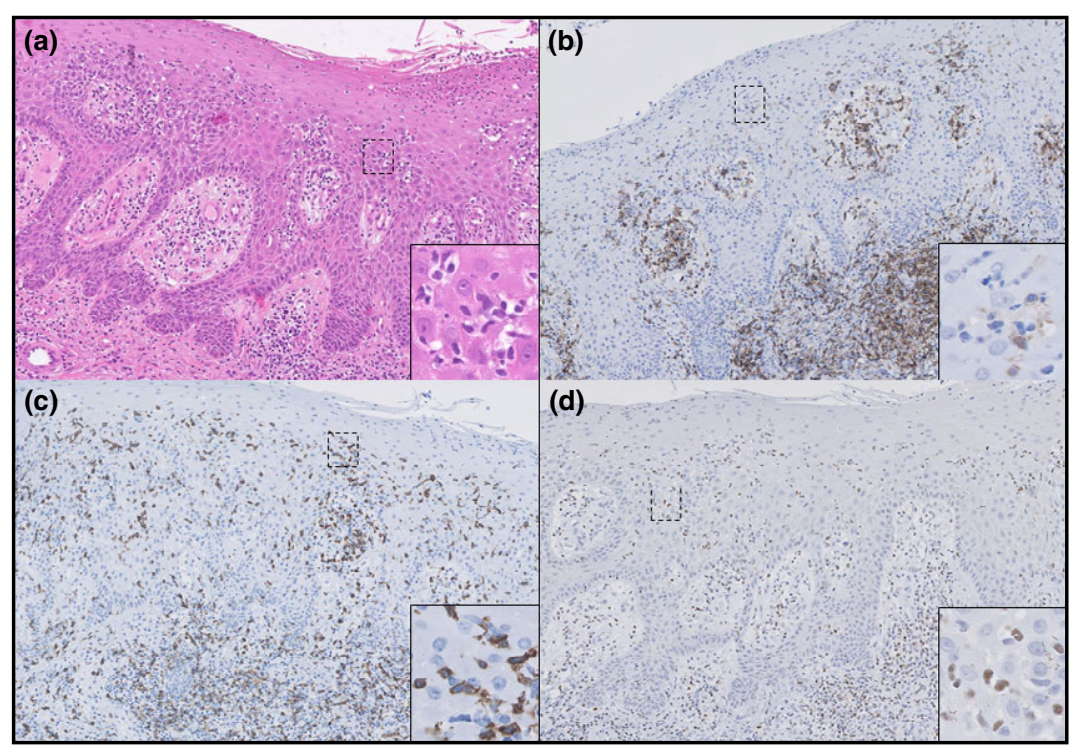


Unexpectedly, the reactive lymph nodes and tonsils that were included in every section as an external control showed TOX expression not only by scattered T cells in the interfollicular areas, but also in the reactive follicles. Additional studies showed that TOX has a similar distribution pattern as BCL6, a marker of germinal center cells, and is also expressed by the neoplastic B-cells of primary cutaneous follicle center lymphomas and other B-cell lymphomas expressing BCL6. ${ }^{14}$

\section{Discussion}

Consistently with previous studies, strong expression of TOX by $>50 \%$ of neoplastic $\mathrm{T}$ cells was found in most cases of MF (49 of 59 patients, $83 \%$ ) and SS (19 of 22 patients, 86\%), while expression of TOX by $>50 \%$ of the skin-infiltrating T cells was found in only one of 60 patients with BIDs $(2 \%))^{2,6-11}$

However, while other studies reported that TOX is expressed only by $\mathrm{CD}^{+}{ }^{+}$neoplastic $\mathrm{T}$ cells in $\mathrm{MF}$ and $\mathrm{SS},{ }^{2,6-}$ 11,15 in the present study, TOX was expressed not only in 35 of 36 patients $(97 \%)$ with $\mathrm{CD} 4^{+} \mathrm{CD}^{-} \mathrm{MF}$, but also in five of eight patients $(63 \%)$ with $\mathrm{CD}^{-} \mathrm{CD}^{+} \mathrm{MF}$ and 10 of 16 patients $(63 \%)$ with $\mathrm{CD}^{-} \mathrm{CD} 8^{-} \mathrm{MF}$. In addition, TOX was expressed in other CTCLs with a $\mathrm{CD}^{-} \mathrm{CD} 8^{+}$phenotype, including one patient with lymphomatoid papulosis, one patient with PTCL-NOS and one patient with AETCL.

In BIDs, most previous studies reported no or few $\mathrm{TOX}^{+} \mathrm{T}$ cells and suggested that TOX expression may be a useful marker for early diagnosis of MF and SS. However, the present study indicates that some caution is warranted. Although TOX expression by $>50 \%$ of the skin-infiltrating $\mathrm{T}$ cells was observed in only one of 60 cases of BID (2\%), 35 of 60 cases (58\%) showed considerable numbers of $\mathrm{TOX}^{+} \mathrm{T}$ cells varying between $11 \%$ and $50 \%$. TOX staining in these T cells was generally dim, but a few scattered blast cells and epidermotropic $\mathrm{T}$ cells, particularly $\mathrm{CD}^{-} \mathrm{CD}^{+}$intraepidermal $\mathrm{T}$ cells in atopic dermatitis, showed strong expression of TOX. These observations suggest that the presence of $\mathrm{TOX}^{+} \mathrm{T}$ cells in itself is insufficient for a diagnosis of MF or SS, but that it should always be considered in conjunction with other clinical and histological data.

TOX expression in reactive and neoplastic $\mathrm{T}$ cells and its biological significance are as yet unexplained. In CTCL, it has been suggested that it is the result of dedifferention. ${ }^{16}$ However, the expression of TOX in a significant proportion of reactive $\mathrm{T}$ cells in BIDs argues against this suggestion. In PCSM-TCL, the overall expression of TOX was very similar to the expression of PD-1. PD-1 is a marker not only of follicular helper $\mathrm{T}$ cells, but also of activated $\mathrm{T}$ cells, and, just like TOX, it is involved in the development of thymocytes during both $\beta$-selection and positive selection. ${ }^{3,17}$ The similar expression patterns of TOX and PD-1 and strong expression of TOX in a few scattered blasts in reactive infiltrates suggest that TOX might also be a marker of activated $\mathrm{T}$ cells, although a previous study was unable to show this in vitro. ${ }^{12}$ In both MF and SS, high levels of TOX have been associated with a worse prognosis. $^{7,12}$ Studies in CTCL cell lines also suggest a role for TOX in the pathogenesis of CTCL. Overexpression of TOX in an MF cell line increased proliferation and migration, while knockdown of TOX in CTCL cell lines induced apoptosis and decreased proliferation and tumour growth. ${ }^{9,12}$

In conclusion, TOX is expressed by various types of CTCL and is therefore not tumour specific. Moreover, it is expressed not only by CTCL with a $\mathrm{CD} 4^{+} \mathrm{CD} 8^{-}$phenotype, but also by CTCL with $\mathrm{CD} 4^{-} \mathrm{CD} 8^{+}$and $\mathrm{CD} 4^{-} \mathrm{CD} 8^{-}$phenotypes. Finally, as considerable amounts of reactive $\mathrm{T}$ cells in BIDs expressed TOX, although less strongly and in lower percentages than in CTCL, TOX expression in itself is insufficient for a diagnosis of CTCL, but it may have an adjunctive diagnostic role in conjunction with other clinical and histological data.

\section{References}

1 Willemze R, Jaffe ES, Burg G et al. WHO-EORTC classification for cutaneous lymphomas. Blood 2005; 105:3768-85.

2 Zhang Y, Wang Y, Yu R et al. Molecular markers of early-stage mycosis fungoides. J Invest Dermatol 2012; 132:1698-706.

3 Wilkinson B, Chen JY, Han P et al. TOX: an HMG box protein implicated in the regulation of thymocyte selection. Nat Immunol 2002; 3:272-80.

4 Kioussis D. Thymocyte differentiation: it's time to bend a little. Nat Immunol 2002; 3:214-15.

5 Aliahmad P, Kaye J. Development of all CD4 T lineages requires nuclear factor TOX. J Exp Med 2008; 205:245-56.

6 McGirt LY, Adams CM, Baerenwald DA et al. miR-223 regulates cell growth and targets proto-oncogenes in mycosis fungoides/cutaneous T-cell lymphoma. J Invest Dermatol 2014; 134:1101-7.

7 Huang Y, Litvinov IV, Wang Y et al. Thymocyte selection-associated high mobility group box gene (TOX) is aberrantly overexpressed in mycosis fungoides and correlates with poor prognosis. Oncotarget 2014; 5:4418-25.

8 Morimura S, Sugaya M, Suga H et al. TOX expression in different subtypes of cutaneous lymphoma. Arch Dermatol Res 2014; 306:843-9.

9 Yu X, Luo Y, Liu J et al. TOX acts an oncological role in mycosis fungoides. PLoS ONE 2015; 10:e0117479.

10 Litvinov IV, Netchiporouk E, Cordeiro B et al. The use of transcriptional profiling to improve personalized diagnosis and management of cutaneous T-cell lymphoma (CTCL). Clin Cancer Res 2015; 21:2820-9.

11 Boonk SE, Cetinozman F, Vermeer MH et al. Differential expression of TOX by skin-infiltrating T cells in Sézary syndrome and erythrodermic dermatitis. J Cutan Pathol 2015; 42:604-9.

12 Huang Y, Su MW, Jiang X, Zhou Y. Evidence of an oncogenic role of aberrant TOX activation in cutaneous T-cell lymphoma. Blood 2015; 125:1435-43.

13 Cetinozman F, Jansen PM, Willemze R. Expression of programmed death-1 in primary cutaneous CD4-positive small/medium-sized pleomorphic T-cell lymphoma, cutaneous pseudo-T-cell lymphoma, and other types of cutaneous T-cell lymphoma. Am J Surg Pathol 2012; 36:109-16.

14 Schrader AM, Jansen PM, Willemze R. TOX expression in cutaneous B-cell lymphomas. Arch Dermatol Res 2016; 308:423-7.

15 Ichimura Y, Sugaya M, Morimura S et al. Two cases of CD8-positive hypopigmented mycosis fungoides without TOX expression. Int J Dermatol 2016; 55:e164-7.

16 Odum N. Malignant TOXication of T cells. Blood 2015; 125:1361-2.

17 Nishimura H, Honjo T, Minato N. Facilitation of beta selection and modification of positive selection in the thymus of PD-1-deficient mice. J Exp Med 2000; 191:891-8. 